\title{
RELAÇÕES ENTRE CONHECIMENTO BÁSICO, ADAPTAÇÃO ACADÊMICA E AUTOEFICÁCIA NA FORMAÇÃO SUPERIOR EM ENGENHARIA
}

DOI: 10.37702/2175-957X.COBENGE.2021.3627

Cristiane Maria Barra da Matta - cristianebarra@maua.br Instituto Mauá de Tecnologia

R. Francisco Cruz 462

04117-091 - São Paulo - SP

Eduardo Nadaleto da Matta - eduardonadaleto@maua.br Instituto Mauá de Tecnologia

Rua Francisco Cruz 462

04117-091 - São Paulo - SP

Marcelo Marques Gomes - marcelo.gomes@maua.br Instituto Mauá de Tecnologia

Praça Mauá 01

09580-900 - São Caetano do Sul - SP

Daniel Kashiwamura Scheffer - daniel.scheffer@maua.br Instituto Mauá de Tecnologia

Rua Doutor Baeta Neves 590

09751-030 - São Bernardo do Campo - SP

Resumo: As dificuldades inerentes do início da vida acadêmica de um curso de Engenharia e da transição da adolescência à vida jovem adulta podem desfavorecer a adaptação universitária, assim como algumas das características intrapessoais, por exemplo, as crenças de autoeficácia. $O$ estudo avaliou a relação entre conhecimento básico, demonstrado pelo desempenho no vestibular, características sociodemográficas, adaptação acadêmica e autoeficácia. Utilizou-se - Questionário de Dados Sociodemográficos, o de Vivência Acadêmica - reduzido (QVA-r) e a Escala de Autoeficácia na Formação Superior (AEFS), assim como as notas dos alunos no concurso vestibular. Participaram do estudo 334 ingressantes do curso de engenharia de uma instituição privada, majoritariamente do sexo masculino, com idade média de 18,3 anos. Os resultados obtidos na pesquisa 
mostraram que a deficiência no conhecimento básico está relacionada com os fatores socioeconômicos, e essa pode desfavorecer as crenças de autoeficácia, dificultando a adaptação ao ensino superior e o sucesso acadêmico. A rede de apoio composta por amigos, familiares e professores é o caminho para reduzir parcialmente os efeitos negativos da deficiência do conhecimento básico.

Palavras-chave: Adaptação acadêmica. Autoeficácia. Vestibular. Conhecimento básico. Ensino Superior. 


\section{(c) COBENGE \\ RELAÇÕES ENTRE CONHECIMENTO BÁSICO, ADAPTAÇÃO ACADÊMICA E AUTOEFICÁCIA NA FORMAÇÃO SUPERIOR EM ENGENHARIA}

\section{INTRODUÇÃO}

A adaptação acadêmica discutida no presente estudo considera como os fatores pessoais e interpessoais se relacionam aos sentimentos dos estudantes quanto à carreira escolhida, aos estudos, à gestão do tempo, e à apreciação quanto à instituição que eles ingressaram.

Já a autoeficácia descrita apresenta a confiança percebida quanto à capacidade acadêmica, na regulação da formação, na interação social, em ações proativas e na gestão acadêmica.

Nesta pesquisa, foram avaliados ingressantes de engenharia, por comporem uma amostra de interesse, visto as dificuldades de adaptação quanto à fase de transição desenvolvimental e ao nível de exigência e dedicação aos estudos no nível superior de ensino.

Nesse contexto, a pesquisa buscou relações entre o conhecimento básico, expresso pelo desempenho no vestibular, as crenças de autoeficácia na formação superior e a percepção de adaptação acadêmica, representada pelas vivências acadêmicas.

\section{REFERENCIAL TEÓRICO}

Os estudantes de engenharia podem apresentar elevados índices de dificuldade na sua formação, além de reprovações em disciplinas do curso (Kieckow, Freitas \& Liesenfeld, 2018; Matta, Lebrão \& Heleno, 2017).

Nesse contexto, entende-se a importância da adaptação acadêmica, ajustamento à vida universitária, que corresponde às exigências de desempenho, ajustamento a novas regras da instituição e a novos colegas, professores e funcionários. Os jovens deparam-se com a necessidade de assumir uma postura ativa frente à aprendizagem, buscando conhecimento e oportunidades de atividades extraclasse (Soares, Poube, \& Mello, 2009; Teixeira, Dias, Wottrich, \& Oliveira, 2008).

Família, amigos e escola constroem a rede de apoio dos calouros, aquela que poderia ser ativada em momentos críticos, fomentando o sentimento de pertença, a busca de soluções e atividades compartilhadas (Dessen \& Polonia, 2007; Oliveira \& Dias, 2014). A convivência diária com a família fortalece esse apoio, uma vez que o prolongamento dos estudos parece estar associado ao adiamento da saída da casa dos pais (Brandão, Saraiva, \& Matos, 2012).

Bandura (1997) conceituou autoeficácia como as crenças que o indivíduo tem sobre sua própria capacidade para organizar e executar determinada ação, influenciando o modo como as pessoas se sentem, pensam, são motivadas e se comportam. Assim, uma atitude positiva quanto ao futuro, associada a uma percepção de autoeficácia e a atribuição de importância a projetos futuros, poderia contribuir para os jovens vivenciarem de forma construtiva os desafios do ensino superior (Soares \& Del Prette, 2015).

Brites-Ferreira et al. (2011) relata que os níveis de sucesso podem ser medidos pelas competências intelectuais e de performance anterior demonstrada; pelos níveis de motivação (sugere-se que os alunos mais motivados para o sucesso apresentam, em geral, 
notas superiores); pelas crenças de autoeficácia que parecem ser também um dos fortes preditores do sucesso acadêmico; pelas estratégias de estudo utilizadas pelos alunos; pelas percepções de autocompetências cognitivas e metacognitivas; pela adaptação e integração ao próprio curso; pelo conhecimento prévio; e pelos níveis de satisfação que os alunos demonstram com o seu rendimento global.

Um estudo com 314 estudantes da Universidade do Minho dos cursos de Ciências e Engenharias, Ciências Sociais e Humanas, e Ciências Econômicas apontou a importância da nota de acesso ao ensino superior na predição do rendimento acadêmico. Os resultados pareceram evidenciar que, mais do que a qualidade das experiências dos alunos em contexto universitário, são as características pré-universitárias (nomeadamente no que se refere aos níveis de preparação acadêmica, mensurados pelas notas de acesso do estudante ao ensino superior) que mais parecem determinar o percurso e sucesso acadêmico do aluno no final do primeiro ano (Almeida et al., 2007).

\section{MÉTODO}

\subsection{Delineamento e procedimentos}

Trata-se de uma pesquisa descritiva, transversal, realizada após a aprovação pelo Comitê de Ética em Pesquisa CAE (omitido). Os alunos foram convidados à participação espontânea, durante um encontro com os professores tutores. Após leitura e assinatura do Termo de Consentimento Livre e Esclarecido (TCLE) procedeu-se à aplicação do instrumento em sala de aula com computadores.

\subsection{Participantes}

Participaram do estudo 334 universitários ingressantes, por vestibular, nos cursos de Engenharia de uma instituição privada do estado de São Paulo, com idade média de 18,3 anos (DP $=0,9)$, majoritariamente do sexo masculino $(64,1 \%)$ e matriculados no período diurno $(84,4 \%)$. A maioria dos estudantes $(91,4 \%)$ estudou em escola particular, $89,5 \%$ deles não trabalhavam e $87,4 \%$ contavam com a família para custear os estudos. Somente $7,5 \%$ possuíam bolsa de estudos ou crédito educativo.

\subsection{Instrumentos}

Foram utilizados o Questionário de Dados Sociodemográficos, para verificar as características individuais dos estudantes (gênero, idade, ensino médio público ou privado, período escolar, situação de trabalho e principal fonte de recursos para custear os estudos), o Questionário de Vivências Acadêmicas - versão reduzida (QVA-r), como uma medida global de adaptação acadêmica (Granado et al., 2005) e a Escala de Autoeficácia na Formação Superior (Polydoro \& Guerreiro-Casanova, 2010).

O instrumento QVA-r avalia as cinco áreas descritas na introdução desse estudo. O questionário é respondido em uma escala tipo Likert que varia de "nada a ver comigo" (1 ponto) a "tudo a ver comigo" (5 pontos). No presente estudo a análise de confiabilidade do QVA-r, representada pelo alfa de Cronbach $(\alpha)$, é de 0,859 para a dimensão pessoal, 0,859 para interpessoal, 0,857 para carreira, 0,828 para estudo e 0,694 para institucional. A dimensão Pessoal investiga o bem-estar físico e psicológico, equilíbrio emocional, estabilidade afetiva, otimismo e autoconfiança; Interpessoal investiga as relações com os colegas, competências de relacionamento em situações de maior intimidade, estabelecimento de amizades e procura de ajuda; Carreira relaciona sentimentos relacionados ao curso, perspectivas de carreira e projetos profissionais; Estudo envolve hábitos de estudo, gestão de tempo, utilização de recursos de aprendizagem no campus e 
preparação para avaliações; e Institucional investiga a apreciação dos alunos quanto à instituição de ensino que frequentam, desejo de permanecer ou mudar de instituição, e conhecimento e apreciação da infraestrutura

A escala AEFS verifica a percepção do estudante em relação à capacidade referente aos diversos aspectos que compõem as experiências no ensino superior. Essa tem formato tipo Likert com dez níveis de resposta, variando de 1 (pouco) a 10 (muito) e seus itens são agrupados em cinco dimensões: autoeficácia acadêmica (confiança percebida na capacidade de aprender, demonstrar e aplicar o conteúdo do curso, com $\alpha=0,90$ ), autoeficácia na regulação da formação (confiança percebida na capacidade de estabelecer metas, fazer escolhas, planejar e autorregular suas ações no processo de formação e desenvolvimento de carreira, com $\alpha=0,89$ ), autoeficácia na interação social (confiança percebida na capacidade de relacionar-se com os colegas e professores com fins acadêmicos e sociais, com $\alpha=0,77$ ), autoeficácia em ações proativas (confiança percebida na capacidade de aproveitar as oportunidades de formação, atualizar os conhecimentos e promover melhorias institucionais, com $\alpha=0,87$ ) e autoeficácia na gestão acadêmica (confiança percebida na capacidade de envolver-se, planejar e cumprir prazos em relação às atividades acadêmicas, $\operatorname{com} \alpha=0,83$ ).

Os coeficientes de confiabilidade $(\alpha)$ obtidos denotam boa consistência interna dos instrumentos para a amostra pesquisada.

\subsection{Procedimento de análise dos dados}

As respostas obtidas no Questionário de Dados Sociodemográficos, no QVA-r e na AEFS, além do desempenho no concurso vestibular, compuseram o banco de dados, a partir do qual foram realizadas análises estatísticas por meio do programa Statistical Package for The Social Science (SPSS) versão 22 (IBM, 2013). Foram efetuadas análises exploratórias dos dados a fim de verificar a precisão da entrada de dados e as pontuações atípicas (outliers). Os valores omissos foram excluídos pelo método listwise (que elimina os casos que possuem qualquer valor omisso), assim como os casos atípicos. A aderência dos dados à distribuição normal foi analisada por meio do teste de Kolmogorov-Smirnov.

Buscou-se caracterizar a amostra, comparando as médias entre os grupos (Teste tStudent e testes de comparações múltiplas) nas variáveis: gênero, escolaridade dos pais, ensino médio público ou privado, situação de trabalho, principal fonte de recurso para custear os estudos e período cursado (diurno e noturno). A direção e o grau da correlação entre as variáveis vivências acadêmicas, autoeficácia e desempenho no vestibular foram examinados por meio da correlação bivariada $\rho$ de Spearman, considerado um teste não paramétrico, pois as variáveis não se adequaram à distribuição normal. Sobre a magnitude do relacionamento, valores entre 0,90 a 0,70 foram considerados altos; entre 0,69 a 0,40, moderados; entre 0,39 a 0,10, fracos (Dancey \& Reidy, 2013).

\section{RESULTADOS}

\subsection{Adaptação acadêmica, autoeficácia e características dos estudantes}

Verificou-se que os estudantes provenientes de escola pública, os que trabalham e os que utilizam recursos próprios para custear o curso, comparativamente com recursos familiares e crédito/bolsa, perceberam-se menos confiantes na capacidade de aprender e demonstrar o conteúdo ( $p \leq 0,05)$.

Não foi observada diferença estatística entre autoeficácia e participantes dos períodos diurno e noturno $(p>0,05)$, visto que muitos alunos do curso noturno não trabalham e são custeados pela família. 
Os alunos que trabalham demonstraram reduzida adaptação quanto à gestão acadêmica, ou seja, baixa confiança percebida na capacidade de envolver-se, planejar e cumprir prazos em relação às atividades acadêmicas, visto a menor carga horária disponível para as tarefas escolares e os estudos.

Bandura (2008) descreve que as emoções positivas aumentam a autoeficácia percebida, enquanto as emoções negativas a diminuem (como ansiedade e estresse), bem como o sono e o cansaço físico podem gerar um fraco julgamento da capacidade e da competência frente à determinada situação, denotando uma baixa crença de autoeficácia. De fato, a falta de sono e o cansaço físico estão mais presentes nos alunos trabalhadores e esses fatores resultam em contribuições para a redução nas crenças de autoeficácia.

Não foi observada diferença significativa entre adaptação acadêmica e características dos estudantes $(p>0,05)$. No entanto, os estudantes provenientes de escola pública e os que trabalham têm maior apreciação quanto à instituição que estudam, mostrando melhor adaptação institucional $(p \leq 0,05)$. Esse resultado evidencia a satisfação desses estudantes em relação à instituição cursada, por terem experimentado piores escolas anteriormente.

\subsection{Nota média de acesso à universidade e características dos estudantes}

O exame vestibular foi realizado no ano anterior ao início da vida universitária. Nessa prova, foram contempladas as disciplinas Redação, Português, Inglês, Matemática, Física, Química, Biologia e Conhecimentos Gerais (História, Geografia e Atualidades). A partir das notas parciais dessas disciplinas foi calculada a média de cada estudante, para obter a classificação do desempenho, e essa foi utilizada no estudo.

Os estudantes calouros que aproveitaram a nota do ENEM ou de vestibulares de anos anteriores na mesma instituição para o acesso à universidade, ou ainda ingressaram por transferência externa não participaram dessa pesquisa.

A comparação entre a nota média do vestibular em função do gênero não foi significativa $(p>0,05)$. No entanto, o desempenho médio no vestibular foi 1 ponto menor para os estudantes provenientes de escola pública, se comparado à privada; 0,75 pontos menor para os alunos que trabalham, se comparado aos que não trabalham e 1 ponto menor para os que utilizam recursos próprios para custear o curso, se comparado aos recursos familiares. Tais comparações apresentam $p \leq 0,05$. O desempenho máximo pontuava 10 pontos. Os resultados foram apresentados na Tabela 1 e na Tabela 2.

Tabela 11 - Análise comparativa do desempenho no vestibular em função do ensino médio e da situação de trabalho.

\begin{tabular}{lcccc}
\hline \multicolumn{1}{c}{ Situação } & N & Média & DP & Valor-p* \\
\hline Ensino médio Público & 29 & 3,46 & 0,96 & $\mathrm{p}=0,000$ \\
Ensino médio Privado & 296 & 4,47 & 1,18 & \\
\hline Aluno que não trabalha & 290 & 4,46 & 1,19 & $\mathrm{p}=0,000$ \\
Aluno trabalhador & 35 & 3,71 & 1,03 & \\
\hline
\end{tabular}

* Valor-p referente ao Teste $t$ de Student para comparação das variáveis entre 2 grupos.

Fonte: Resultado da pesquisa. 
Tabela 2 - Análise comparativa do desempenho no vestibular e principal fonte de recursos para custear os estudos.

\begin{tabular}{lcccc}
\hline Recurso para Custear o Curso & N & Média & DP & Valor-p** \\
\hline Próprio & 12 & 3,47 & 1,02 & \\
Familiar & 283 & 4,49 & 1,18 & $\mathrm{p}=0,000$ \\
Bolsa ou crédito & 25 & 3,62 & 1,14 & \\
\hline ** Valor-p referente à análise de variância (ANOVA) &
\end{tabular}

** Valor-p referente à análise de variância (ANOVA) para comparação das variáveis entre 3 grupos.

Fonte: Resultado da pesquisa.

Os resultados refletem algo já esperado, que os alunos que possuem condições socioeconômicas mais desfavoráveis, com ensino básico público e que trabalham para custear seu curso superior, apresentaram menor desempenho no vestibular. $O$ ensino básico público na maior parte das vezes resulta em ensino de menor qualidade, se comparado às escolas particulares, oferecendo menos conteúdo, muitos deles essenciais para o curso de Engenharia.

Nascimento (2017) relatou, ainda, que os estudantes da área de Engenharia, em sua maioria, são homens, brancos e pardos, e estudaram o ensino médio em escolas privadas. Também apresentou o reduzido ingresso de estudantes da rede pública, principalmente, nas instituições que não apresentavam um sistema diferenciado com a reserva de vagas (cotas) de ingresso em seus vestibulares, considerando os critérios socioeconômicos, raciais ou origem escolar. Ele também ressaltou que as universidades nas quais havia alguma política de ação afirmativa (cotas) proporcionaram uma entrada maior de estudantes da rede pública.

Segundo Caprara, et al. (2008) e Zago (2006) o nível socioeconômico relaciona-se com as notas e pode contribuir para o abandono escolar, visto as desigualdades existentes em nosso país, sendo a entrada na universidade um investimento para ampliar as chances no mercado de trabalho.

\subsection{Correlação entre conhecimento básico e vivências acadêmicas}

A Figura 1 apresenta a dispersão dos resultados médios obtidos no vestibular e nas dimensões das vivências acadêmicas. Nota-se uma tendência crescente entre a dimensão carreira e as demais dimensões do instrumento, e as dimensões pessoal e estudo com média no vestibular.

Diante desse resultado, observou-se que os sentimentos positivos relacionados ao curso e às perspectivas de carreira favoreceram a adaptação acadêmica.

Alunos com melhores classificações no ensino médio geralmente apresentam uma aprendizagem mais sólida e aprofundada no ensino superior (Santos, 2000), assim como melhor desempenho no vestibular. Monteiro, Vasconcelos e Almeida (2005) relataram que as abordagens à aprendizagem influenciam a variabilidade do desempenho escolar, não só no ensino fundamental e médio, mas também no ensino universitário, ao analisarem os métodos de estudo de alunos do primeiro ano dos cursos de Engenharia. 
Figura 1 - Dispersão dos resultados da nota média no vestibular e das dimensões das vivências acadêmicas.

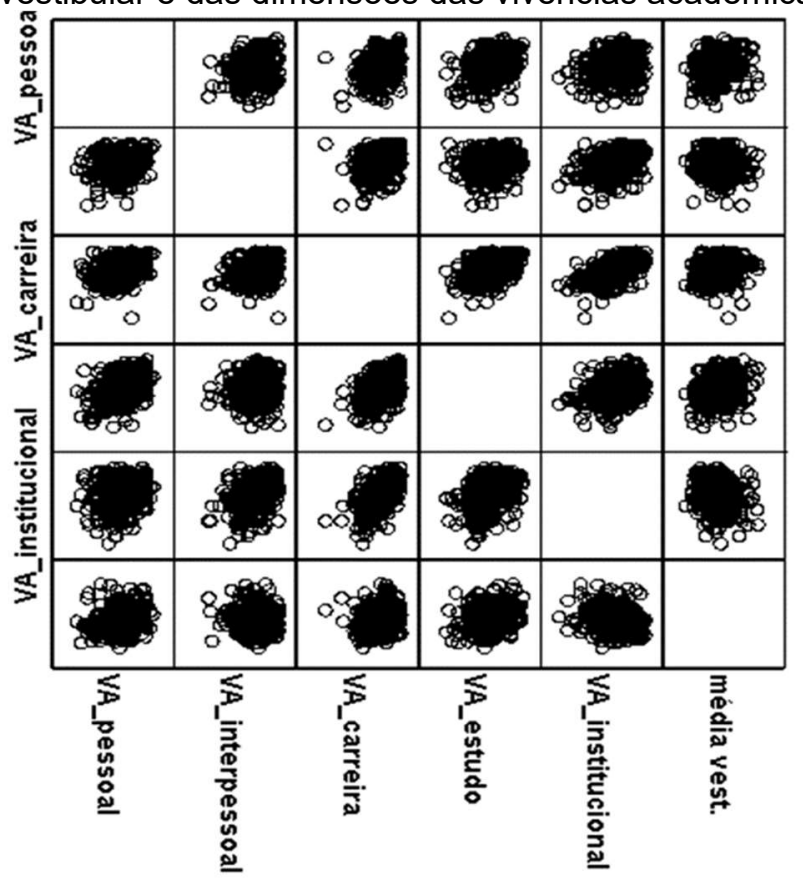

Fonte: Resultado da pesquisa.

Os resultados da Tabela 3 mostram que existe uma correlação positiva entre média das notas no vestibular e três dimensões de adaptação: pessoal, carreira e estudo $(p \leq 0,05)$. Assim, um melhor desempenho no vestibular, proveniente de um maior conhecimento básico, favoreceu a adaptação nas questões pessoais (bem-estar, equilíbrio emocional, otimismo e autoconfiança), quanto ao curso e à profissão escolhida, e aos estudos e à gestão de tempo.

Tabela 3 - Coeficientes de correlação ( $\rho$ de Spearman) entre média das notas no vestibular e as dimensões de vivências acadêmicas (VA).

\begin{tabular}{lcccccc}
\hline & Vestibular & $\begin{array}{c}\text { VA } \\
\text { Pessoal }\end{array}$ & $\begin{array}{c}\text { VA } \\
\text { Interpessoal }\end{array}$ & $\begin{array}{c}\text { VA } \\
\text { Carreira }\end{array}$ & $\begin{array}{c}\text { VA } \\
\text { Estudo }\end{array}$ & $\begin{array}{c}\text { VA } \\
\text { Institucional }\end{array}$ \\
\hline Vestibular & 1 & & & & & \\
VA Pessoal & $0,208^{*}$ & 1 & & & & \\
VA Interpessoal & $-0,110^{* *}$ & $0,191^{*}$ & 1 & & & \\
VA Carreira & $0,169^{*}$ & $0,304^{*}$ & $0,284^{*}$ & 1 & & \\
VA Estudo & $0,238^{*}$ & $0,368^{*}$ & $0,223^{*}$ & $0,424^{*}$ & 1 & 1 \\
VA Institucional & $-0,148^{*}$ & $0,160^{*}$ & $0,377^{*}$ & $0,586^{*}$ & $0,359^{*}$ & 1 \\
\hline
\end{tabular}

${ }^{*}$ Valor-p $\leq$ 0,01, **Valor-p $\leq$ 0,05

Fonte: Resultado da pesquisa.

Apesar de uma relação fraca, uma maior bagagem de conhecimento, proveniente da escola básica, poderia assegurar aos alunos alguma tranquilidade face ao desafio da aquisição de novos conhecimentos, habilidades e atitudes previstos na universidade, facilitando sua adaptação pessoal (Soares e Del Prette, 2015), ao curso e ao estudo. 
As outras duas dimensões, interpessoal $(p=0,048)$ e institucional $(p=0,007)$, possuem correlações negativas com os resultados do vestibular, demonstrando que os estudantes com menor desempenho no vestibular têm maior percepção de estabelecimento de amizade e maior apreciação da instituição que estudam, possivelmente por terem frequentado piores escolas. Todas as relações com vestibular são significativas, porém, fracas.

As relações moderadas são da dimensão estudo com carreira e da dimensão institucional com carreira. Aqui vale ressaltar que a adaptação se torna efetiva se houver hábitos de estudo, bons sentimentos relacionados ao curso e à instituição, apoio e boas amizades, otimismo e bem-estar pessoal.

Autores relataram que as relações interpessoais com a família, colegas e professores podem ser preditivas da adesão ao curso e à instituição de nível superior, bem como do ajustamento pessoal e social do aluno a esta nova realidade, uma vez que interferem nos modelos de organização dos jovens estudantes (Soares \& Del Prette, 2015). Essa rede de apoio dos calouros fortalece o sentimento de pertença, a busca de soluções e as atividades compartilhadas, principalmente nas convivências diárias (Dessen \& Polonia, 2007; Oliveira \& Dias, 2014; Brandão, Saraiva, \& Matos, 2012).

Além do sentimento de pertencimento e de autoestima, os relacionamentos auxiliam na construção da identidade do indivíduo e na construção de seus ideais, valores e objetivos para a vida adulta (Cordeiro, 2006).

$\mathrm{Na}$ instituição pesquisada, as práticas de boas-vindas e de acolhimento aos alunos ingressantes são desenvolvidas ao longo no primeiro semestre do curso, em um programa de tutoria, para que eles possam formar um conjunto de habilidades que lhes permitam conviver plenamente na sociedade acadêmica, assim como sugerido por Soares, Francischetto, Peçanha, Miranda e Dutra (2013). Algumas das práticas e o contexto acadêmico da instituição pesquisada favoreceram a boa adaptação dos ingressantes à vida acadêmica, refletindo no comportamento, na qualidade dos relacionamentos, no envolvimento, no rendimento e na satisfação.

Apesar das importantes informações fornecidas pelo uso do QVA-r, autores salientam que esse não deve ser tomado como critério exclusivo para avaliar a adaptação dos estudantes universitários; aspectos de saúde como problemas genéticos e enfermidades graves, composição familiar e fatores econômicos também devem ser levados em consideração (Rodriguez, Urazán, \& Arango, 2009).

\subsection{Correlação entre conhecimento básico e autoeficácia no ensino superior}

Nos gráficos de dispersão dos resultados médios obtidos no vestibular e nas dimensões da autoeficácia (Figura 2) observa-se uma tendência crescente mais acentuada somente entre as dimensões de autoeficácia, mas não com os dados do vestibular. 
Figura 2 - Dispersão dos resultados da nota média no vestibular e das dimensões da autoeficácia.

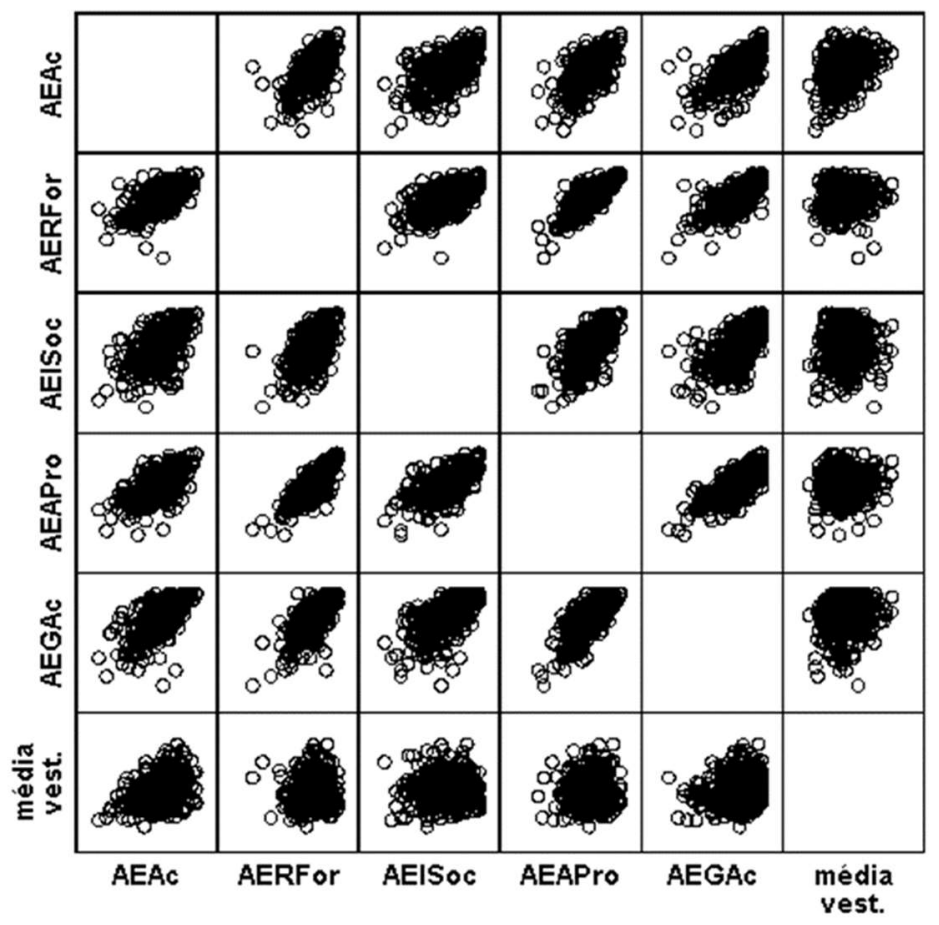

Fonte: Resultado da pesquisa.

Os resultados da Tabela 4 mostram que existe uma correlação significativa e positiva entre autoeficácia acadêmica e na gestão acadêmica com nota de acesso à universidade $(p \leq 0,05)$, porém, ambas de magnitude fraca.

Tabela 4 - Coeficientes de correlação ( $\rho$ de Spearman) entre médias das notas obtidas no vestibular e as dimensões de autoeficácia (AE).

\begin{tabular}{lcccccc}
\hline & Vestibular & $\begin{array}{c}\mathrm{AE} \\
\text { Acadêmica }\end{array}$ & $\begin{array}{c}\mathrm{AE} \\
\text { Regulação }\end{array}$ & $\begin{array}{c}\mathrm{AE} \text { Int. } \\
\text { Sociais }\end{array}$ & $\begin{array}{c}\mathrm{AE} \\
\mathrm{Ações}\end{array}$ & $\begin{array}{c}\mathrm{AE} \\
\text { Gestão }\end{array}$ \\
\hline Vestibular & 1 & & & & & \\
AE Acadêmica & $0,353^{*}$ & 1 & & & & \\
AE Regulação & 0,020 & $0,650^{*}$ & 1 & & & \\
AE Int. Sociais & 0,036 & $0,531^{*}$ & $0,605^{*}$ & 1 & & \\
AE Ações & 0,060 & $0,647^{*}$ & $0,783^{*}$ & $0,655^{*}$ & 1 & 1 \\
AE Gestão & $0,158^{*}$ & $0,688^{*}$ & $0,694^{*}$ & $0,661^{*}$ & $0,715^{*}$ & 1 \\
\hline * Valor-p $\leq 0,01$ & & & & & &
\end{tabular}

*Valor-p $\leq 0,01$

Fonte: Resultado da pesquisa.

A partir dos resultados, entende-se que os conhecimentos previamente adquiridos fortalecem as crenças de capacidade da aprendizagem, do envolvimento e do cumprimento das atividades acadêmicas no prazo.

Além das habilidades e competências necessárias aos alunos de Engenharia, é imprescindível a própria crença de que são capazes de realizar as tarefas, por possuírem 
habilidades e competências (Aleta, 2016), sem isso dificilmente terão sucesso acadêmico (Tinto, 2015; Brites-Ferreira et al., 2011).

Nesse caso, seria interessante que os serviços de apoio ao estudante pudessem realizar oficinas de fortalecimento da autoeficácia, atuação positiva quanto às alterações pessoais no primeiro ano de graduação, orientação de técnicas de estudo e gestão do tempo, de forma a estimular a motivação intrínseca dos ingressantes, conjuntamente com a promoção da integração ao ensino superior, como orientado por Alci (2015). Bandura (1997, 2001, 2008) e Tinto (2015) alertam que a autoeficácia é aprendida, e não herdada e Tinto destaca ainda que ela é a base sobre a qual a persistência do aluno é construída.

\section{CONSIDERAÇÕES FINAIS}

Compreendeu-se que o ingressante universitário enfrenta desafios acadêmicos de aprendizagem e socialização, além dos desenvolvimentais. Alguns ainda vivenciam dificuldades financeiras e carências de capital cultural. Todo esse processo de transição do ingressante, do ensino médio ao ensino superior, e da adolescência à fase jovem adulta, requer comportamentos adaptativos, que devem ser desempenhados de forma competente e prazerosa.

Os fatores socioeconômicos, na maior parte dos casos impactam no capital cultural dos estudantes (antes do ingresso no ensino superior), e consequentemente no desempenho no vestibular, nas crenças de autoeficácia e na adaptação à instituição de ensino. O presente estudo mostrou que os alunos da educação básica pública e que trabalham, os de situação socioeconômica menos favorecida, apresentaram menor crença na capacidade de aprender, que os alunos que estudaram em escolas particulares e não trabalham. Os alunos trabalhadores ainda expressaram menor crença na capacidade de gestão das atividades acadêmicas, por terem menor carga horária disponível para os estudos.

Acredita-se que a rede de apoio, composta por amigos, familiares e professores, possibilita reduzir parcialmente os efeitos negativos da deficiência do conhecimento básico.

Por fim, o conhecimento básico, obtido antes do ingresso no ensino superior, auxilia na adaptação pessoal, ao curso e à carreira de engenharia, assim como favorece as crenças na capacidade de aprender e de gestão do ensino superior.

\section{Agradecimentos}

À FAPESP, pelo apoio financeiro.

À CAPES, pelas bolsas de doutorado concedidas.

\section{REFERÊNCIAS}

$\mathrm{ALCl}, \mathrm{B}$. The influence of self-efficacy and motivational factors on academic performance in general chemistry course: a modeling study. Educational Reserch and Reviews, v. 10, n. 4, p. 453-461, 2015.

ALETA, B. T. Engineering self-efficacy contributing to the academic performance of AMAIUB Engineering Students: a qualitative investigation. Journal of Education and Practise, v. 7, n. 27, p. 53-61, 2016.

ALMEIDA, L. S. et al. Rendimento Académico no Ensino Superior: Estudo com Alunos do $1^{\circ}$ Ano. Revista Galego-Portuguesa de Psicoloxía e Educación, v. 14, n. 1, p. 207-220, 2007. 
BANDURA, A. Self-efficacy, the exercise of control. New York: Freeman, 1997.

BANDURA, A. Social cognitive theory: an agentic perspective. Annual Review of Psychology, v. 52, p. 1-26, 2001.

BANDURA, A. Toward an agentic theory of the self. In: MARSH, H.; CRAVEN, R. G.; MCINERNEY, D. M. SelfProcesses, Learning and Enabling Human Potential: Dynamic New Approaches. Charlotte, NC: Information Age Publishing, v. 3, 2008. p. 15-49.

BRANDÃO, T.; SARAIVA, L.; MATOS, P. M. O prolongamento da transição para a idade adulta e o conceito de adultez emergente: especificidades do contexto português e brasileiro. Análise Psicológica, v. 30, n. 3, p. 301-313, jul 2012.

BRITES-FERREIRA, J. et al. (In)sucesso acadêmico no Ensino Superior: conceitos, fatores e estratégias de intervenção. Revista iberoamericana de educación superior, $v$. 2, n. 4, p. 28-40, 2011.

CAPRARA, G. V. et al. Longitudinal analysis of the role of perceived self-efficacy for selfregulated learning in academic continuance and achievement. Journal of Educational Psychology, v. 100, n. 3, p. 525-534, 2008.

CORDEIRO, R. A. Aparência física e amizade íntima na adolescência: astudo num contexto pré-universitário. Análise Psicológica, Lisboa, v. 4, n. XXIV, p. 509-517, 2006.

DANCEY, C. P.; REIDY, J. Estatística sem matemática para psicologia. 5. ed. Porto Alegre: Penso, 2013. 608 p.

DESSEN, M. A.; POLONIA, A. D. C. A família e a escola como contextos de desenvolvimento humano. Paidéia, v. 17, n. 36, p. 21-32, 2007.

GRANADO, J. I. F. et al. Integração Académica de estudantes universitarios: Contributos para a adaptação e validação do QVA-r no Brasil. Psicologia e Educação, v. 4, n. 2, p. 31-41, 2005.

KIECKOW, F.; FREITAS, D. B. D.; LIESENFELD, J. O ensino e a aprendizagem na engenharia: realidade e perspectivas. Brasilian Applied Science Review, v. 2, n. 1, 20158.

MATTA, C. M. B. D.; LEBRÃO, S. M. G.; HELENO, M. G. V. Adaptação, rendimento, evasão e vivências acadêmicas no ensino superior: revisão da literatura. Psicologia Escolar e Educacional, v. 21, n. 3, p. 583-591, 2017.

MONTEIRO, S.; VASCONCELOS, R.; ALMEIDA, L. S. Rendimento académico: influência dos métodos de estudos. Actas do VIII Congresso Galaico Português de Psicopedagogia. Braga: Universidade do Minho - Centro de Investigação em Educação. 2005.

NASCIMENTO, J. D. D. Mulheres nos cursos de engenharia da UFBA: um estudo sobre o acesso e desempenho. Universidade Federal da Bahia. Salvador. 2017.

OLIVEIRA, C. T. D.; DIAS, A. C. G. Dificuldades na Trajetória Universitária e Rede de Apoio de Calouros e Formandos. Psico, v. 45, n. 2, p. 187-197, 2014. 
POLYDORO, S. A. J.; GUERREIRO-CASANOVA, D. C. Escala de autoeficácia na formação superior: construção e estudo de validação. Avaliação Psicológica, Porto Alegre, v. 9, n. 2, p. 267-278, 2010.

RODRIGUEZ, D. P. ; URAZÁN, S. C. O.; ARANGO, M. I. R. Cuestionario de vivencias académicas en su versión reducida (QVA-r): un análisis psicométrico. Revista Colombiana de Psicología, v. 18, n. 1, p. 33-52, 2009.

SANTOS, L. Vivências académicas e rendimento escolar: estudo com alunos universitários do $1^{\circ}$ ano. Universidade do Minho. Braga. 2000.

SOARES, A. B. et al. Inteligência e competência social na adaptação à universidade. Estudos de Psicologia, v. 30, n. 3, p. 317-328, 2013.

SOARES, A. B.; DEL PRETTE, Z. A. P. Habilidades sociais e adaptação à universidade: Convergências e divergências dos construtos. Análise Psicológica, v. 33, n. 2, p. 139151, 2015.

SOARES, A. B.; POUBE, L. N.; MELLO, T. V. D. S. Habilidades sociais e adaptação acadêmica: um estudo comparativo em instituições de ensino público e privado. Aletheia, v. 29 , p. $27-42,2009$.

TEIXEIRA, M. A. P. et al. Adaptação à universidade em jovens calouros. Psicologia Escolar e Educacional, v. 12, n. 1, p. 185-202, 2008.

TINTO, V. Through the Eyes of Students. Journal of College Student Retention: Research, Theory \& Practice, v. 19, n. 3, p. 254-269, 2015.

ZAGO, N. Do acesso à permanência no ensino superior: percursos de estudantes universitários de camadas populares. Revista Brasileira de Educação, v. 11, n. 32, p. 226-237, 2006.

\section{RELATIONS BETWEEN SCHOOL KNOWLEDGE, ADAPTATION AND HIGHER EDUCATION SELF-EFFICACY IN ENGINEERING}

Abstract: Engineering students hold some difficulties in their early life in college and in the transition from adolescence to young adulthood and this can affect the adaptation to university and certain intrapersonal traits, how self-efficacy beliefs. The study evaluated the relations between school knowledge, demonstrated by initial performance, adaptation and higher education self-efficacy. Was used Sociodemographic Data, Academic Experience Questionnaire - reduced version (QVA-r) and the Self-efficacy Scale in Higher Education (AEFS), as well as data collected from entrance exam. A total of 334 mostly male freshmen from a private engineering school, with the average age of 18.3 years old participated in the study. The results showed that the deficiency in basic knowledge is related to socioeconomic factors, and self-efficacy beliefs, hindering adaptation to higher education and academic success. The support network of friends, family, and teachers is the way to partially reduce the negative effects of basic knowledge deficiency.

Keywords: adaptation to university, self-efficacy, entrance exam, school knowledge, higher education. 